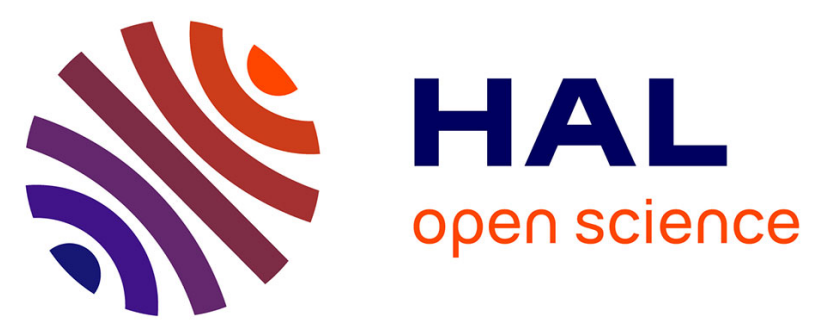

\title{
Analysis of length of stay after transfemoral transcatheter aortic valve replacement: results from the FRANCE TAVI registry
}

Eric Durand, Guillaume Avinée, André Gillibert, Christophe Tron, Nicolas Bettinger, Najime Bouhzam, Martine Gilard, Jean Philippe Verhoye, René Koning, Thierry Lefevre, et al.

\section{To cite this version:}

Eric Durand, Guillaume Avinée, André Gillibert, Christophe Tron, Nicolas Bettinger, et al.. Analysis of length of stay after transfemoral transcatheter aortic valve replacement: results from the FRANCE TAVI registry. Clinical Research in Cardiology, 2021, 110 (1), pp.40-49. 10.1007/s00392-020-01647-4 . hal-02877346

HAL Id: hal-02877346

https://hal-univ-rennes1.archives-ouvertes.fr/hal-02877346

Submitted on 22 Jun 2020

HAL is a multi-disciplinary open access archive for the deposit and dissemination of scientific research documents, whether they are published or not. The documents may come from teaching and research institutions in France or abroad, or from public or private research centers.
L'archive ouverte pluridisciplinaire HAL, est destinée au dépôt et à la diffusion de documents scientifiques de niveau recherche, publiés ou non, émanant des établissements d'enseignement et de recherche français ou étrangers, des laboratoires publics ou privés. 
1 Analysis of Length of Stay after Transfemoral Transcatheter Aortic Valve Replacement: Results from the

\section{FRANCE TAVI Registry}

Eric Durand MD PhD; ${ }^{\mathrm{a}}$ Guillaume Avinée MDª André Gillibert MD ${ }^{\mathrm{b}}$; Christophe Tron MDª Nicolas Bettinger $\mathrm{MDa}^{3}$; Najime Bouhzam MD ${ }^{\mathrm{a}}$; Martine Gilard MD, PhD ${ }^{\mathrm{b}}$; Jean Philippe Verhoye MD ${ }^{\mathrm{c}}$; René Koning MD ; Thierry Lefevre MD ${ }^{\mathrm{e}}$; Eric Van Belle MD, $\mathrm{PhD}^{\mathrm{f}}$; Pascal Leprince MD${ }^{\mathrm{g}}$; Bernard Iung $\mathrm{MD}^{\mathrm{h}}$; Hervé Le Breton MDi; Hélène Eltchaninoff $\mathrm{MD}^{\mathrm{a}}$

Normandie Univ, UNIROUEN, INSERM U1096, Rouen University Hospital, Department of Cardiology, FHU

REMOD-VHF, F76000, Rouen, France ${ }^{\mathrm{a}}$

Department of Biostatistics, CHU de Rouen, F-76000, Rouen, France ${ }^{\mathrm{b}}$

Brest University Hospital, Department of Cardiology, Brest, France ${ }^{\mathrm{c}}$

Rennes University Hospital, Department of Cardiac surgery, Rennes, France ${ }^{\mathrm{d}}$

Clinique Saint Hilaire, Department of cardiology, Rouen, France ${ }^{\mathrm{e}}$

Institut Hospitalier Jacques Cartier, Ramsay Générale de Santé, Department of Cardiology, Massy, France ${ }^{\mathrm{f}}$

CHU Lille, Department of Cardiology, Institut Pasteur de Lille, Lille, France ${ }^{\mathrm{g}}$

Cardiothoracic surgery department, Université Paris 6, Pitié-Salpétrière hospital, institut de cardiologie, AP-HP,

75013 Paris, France ${ }^{\mathrm{h}}$

Assistance Publique-Hôpitaux de Paris, Bichat Hospital, Faculté de Médecine Paris-Diderot, Department of

Cardiology, DHU Fire, INSERM U1148, Paris-Diderot University, Paris, France ${ }^{\mathrm{i}}$

Rennes University Hospital, Department of Cardiology, Rennes, France ${ }^{\mathrm{j}}$

Short title: Length of stay after TAVR

\section{Address for correspondence:}

Eric Durand, MD, PhD

Department of Cardiology, Charles Nicolle Hospital

1 rue de Germont, 76031 Rouen Cedex, France.

Fax number: +33(0)232 880421 ,

Phone number: +33(0)232 888232 ,

E-mail: eric.durand@chu-rouen.fr 
4 Background: Currently, there are no recommendations regarding the minimum duration of in-hospital 5 monitoring after transfemoral (TF) transcatheter aortic valve replacement (TAVR) and practices are extremely 6 heterogeneous. We therefore aimed to evaluate length of stay (LOS) and predictive factors for late discharge 7 after TF TAVR using data from the FRANCE TAVI registry.

8 Methods: TAVR was performed in 12,804 patients in 48 French centers between 2013 and 2015. LOS was 9 evaluated in 5,857 TF patients discharged home. LOS was calculated from TAVR procedure (day 0) to

\section{ABSTRACT} discharge. The study population was divided into 3 groups based on LOS values. Patients discharged within 3 days constituted the "very early" discharge group, patients with a LOS between 3 and 6 days constituted the "early" discharge group, and patients with a length of stay $>6$ days constituted the "late" discharge group.

Results: The median LOS was 7 (5-9) days and was extremely variable among centers. The proportion of patients discharged very early, early, and late was 4.4\% $(\mathrm{n}=256), 33.7 \%(\mathrm{n}=1997)$, and $61.9 \%(\mathrm{n}=3624)$ respectively. Variables associated with late discharge were female sex, co-morbidities, major complications, self expandable valve, general anesthesia, and a significant center effect. In contrast, history of previous pacemaker was a protective factor. The composite of death and re-admission in the very early and early versus late discharge groups were similar at 30 days $(3.3 \%$ vs. $3.5 \%$, $\mathrm{p}=0.66)$.

Conclusions: LOS is extremely variable after TF TAVR in France. Co-morbidities and complications were predictive factors of late discharge after TAVI. Interestingly, the use of self-expandable prosthesis and general anesthesia may also contribute to late discharge. Our results confirm that early discharge is safe.

Key words: aortic stenosis, TAVR, length of stay 
Transcatheter aortic valve replacement (TAVR) is increasingly involved in the management of aortic

4 stenosis. Initially limited to inoperable and high-risk patients, indications for TAVR have now extended to

5 intermediate-risk patients, especially when a femoral approach is feasible [1,2]. After the procedure, patients

6 remain hospitalized to check for complications before being discharged home (or to a rehabilitation center).

7 Currently, there is no recommendation concerning the minimum duration of in-hospital monitoring and practices

8 are extremely heterogeneous [3]. We and others previously demonstrated that early discharge home (i.e., within

93 days after the procedure) was feasible and safe [4-11]. Prolonged unjustified hospitalization can expose

10 patients to potential complications and may not be cost effective.

11 FRANCE TAVI is an all-comers prospective registry of the French Society of Cardiology since 2013

12 and includes all consecutive patients who have TAVR [12]. We aimed to evaluate the length of stay (LOS) after 13 transfemoral (TF) TAVR in patients discharged directly home and predictive factors for prolonged 14 hospitalization. 
Launched in January 2013, FRANCE TAVI is an initiative of GACI, the French Society of Cardiology's working group of interventional cardiology, with the participation of the French Society of Thoracic and Cardiovascular Surgery [12]. Device manufacturers partly funded the registry but had no role in data collection or analysis or in manuscript preparation. Designed as an all-comers registry, it prospectively includes data on all patients who have TAVR for severe aortic stenosis in 48 of 50 active centers in France and who volunteer to participate. FRANCE TAVI was designed in continuity with the FRANCE 2 registry to provide further data on baseline characteristics of patients as well as procedural aspects and clinical outcomes of TAVR recipients on a national scale [13]. The decision to perform TAVR and the choices of approach and device used were made on the basis of assessment by a multidisciplinary heart team at each participating center, as previously described [12]. Procedures and post procedural management were performed in accordance with each site's routine protocol. Follow-up was performed either on site or by telephone contact with the patient or the patient's physician depending on each site's protocol at 30 days and then every year. Patients included in the registry provided written informed consent for the procedure and for anonymous processing of their data. The registry was approved by the Institutional Review Board of the French Ministry of Higher Education and Research and by the National Commission for Data Protection and Liberties. The FRANCE TAVI dataset was collected using a dedicated web-based interface from the French Society of Cardiology. All data, including inhospital complications and follow-up, were site reported according to the definitions within the national dataset. The database was managed by the French Society of Cardiology, which implemented regular data quality checks, including range checks and assessments of internal consistency. In cases of missing, extreme, or inconsistent values, centers were contacted and asked to verify and modify records as appropriate. For the purposes of this analysis, a FRANCE TAVI database encompassing all patients included from January 2, 2013, to December 31, 2015, was locked. Complications were classified using Valve Academic Research Consortium 2 criteria [3]. The safety endpoint was a composite of all-cause mortality or repeat hospitalization 7 within 30 days.

\section{Statistical analysis}

LOS was calculated from TAVR procedure (day 0) to discharge. The study population was divided into 3 groups based on LOS values. Patients discharged within 3 days constituted the very early discharge group, 
patients with a LOS between 3 and 6 days constituted the early discharge group, and patients with a length of stay $>6$ days constituted the "late discharge group"

We created a variable to evaluate a potential center effect on LOS. This variable categorized centers according to median LOS. Centers with a median LOS less than 7 days $(n=13)$ were called "centers with short LOS" whereas centers with a median LOS more than 7 days $(\mathrm{n}=35)$ were called "centers with prolonged LOS".

The volume of the centers was estimated based on tertile values and expressed as low $(<75)$, medium $(75-140)$,

and high (>140) volume groups.

Qualitative variables were expressed as percentage, and quantitative variables as mean $\pm \mathrm{SD}$ or median (25th to 75th interquartile range). Comparison of numerical variables was performed with the Student $t$ test or Wilcoxon rank-sum test, depending on variable distribution. When there were more than 2 groups to compare, and according to the distribution of the variable, an Anova test or a kruskall-Wallis test were used. The chisquare test or Fisher's exact test was used to compare qualitative variables. A logistic regression multivariable analysis was used to assess independent correlates of late discharge (LOS $>6$ days). The model was built on the basis of the univariate association between the variable and late discharge with a $\mathrm{p}<0.10$. The correlation between LOS and volume of activity was assessed using Spearman's rank correlation coefficient. The survival free from rehospitalization was compared between patients with very early/early and late discharge with a logrank test. Then, adjustment for confounders was performed by a matched analysis. First, a general linear model was fitte with LOS by age, sex, EuroSCORE, respiratory failure, history of mitral valve prosthesis, atrial fibrillation, any complication, post-TAVI pacemaker, post-TAVI acute kidney injury, local anesthesia, valve type, center and year of intervention as covariates. This model was used to predict the LOS with the center effect subtracted from the prediction, in order to calculate an excess of LOS compared to the average of the center. Patients with very early/early discharge in centers belonging to the lowest tertile of LOS, were randomly paired l:1 with patients with late discharge in centers belonging to the upper tertile. Then, a matched Cox model was used to compare the survival free from rehospitalization between patients with early and late discharge. In order

o avoid sampling fluctuations due to the random seed used for matching, 512 random matches were performed and the model having the median Hazard Ratio was selected.

All statistical tests were 2 sided. Differences were considered statistically significant at a p value $<0.05$. All data were analyzed using SPSS software (version 23.0; IBM, Armonk, New York). 


\section{RESULTS}

\section{Study flowchart}

The flowchart of the studied population is presented in Figure 1.

From January 2013 to December 2015, 48 out of 50 French centers participated in the FRANCE TAVI registry. A total of 12,804 patients had TAVR during this period [12]. Among them 12,700 (99.2\%) patients were implanted using either a balloon-expandable valve (SAPIEN XT or SAPIEN 3, Edwards LifeSciences, Irvine, California, USA; $\mathrm{n}=8,230$ ) or a self-expandable valve (Medtronic COREVALVE, Minneapolis, 9 Minnesota, USA; $n=4,470)$ via a transfemoral approach in 10,505 (82.7\%) patients. After TF TAVR, 404 (3.8\%) patients died during the index hospitalization, 113,938 (37.5\%) patients were transferred to another institution or

to a rehabilitation center, and the discharge destination was unknown in 306 patients (2.91\%). Thus, 5,857 (55.7\%) TF TAVR patients were discharged directly home and were the studied population.

LOS and predictive factors of late discharge

LOS was highly variable among centers (Figure 2, p<0.001). The median LOS was 7 days (IQR 5-9). Based on LOS values, the study population was divided into 3 groups. The proportion of patients discharged very early within 3 days was very low $(4.4 \%, n=256)$. The proportion of patients discharged early and late was
$33.7 \%(\mathrm{n}=1997)$ and $61.9 \%(\mathrm{n}=3624)$, respectively. The median LOS was $3(3-3)$ days in the very early discharge group, 5 (5-6) days in the early discharge group, and 8 (7-11) days in the late discharge group

$(\mathrm{p}<0.001)$. Baseline characteristics are shown in Table 1. Patients in the very and early discharge groups had lower logistic EuroSCORE $(\mathrm{p}<0.001)$ and had a higher rate of previous pacemaker implantation $(\mathrm{p}=0.02)$. Furthermore, patients in the late discharge group had more frequent COPD, atrial fibrillation, history of surgical mitral valve replacement, and severe pulmonary hypertension (defined by systolic pulmonary artery pressure $>60 \mathrm{mmHg})$.

Procedural characteristics differed also among groups (Table 2). Patients in the very early discharge group had TF TAVR more frequently using local anesthesia $(\mathrm{p}=0.002)$. A self-expandable valve was also more frequently used in the late discharge group $(\mathrm{p}<0.001)$. Moreover, intra-procedural trans oesophageal echography was more frequently used in the early and late discharge groups $(\mathrm{p}<0.001)$. As expected, both groups had a high rate of procedural success and a low rate of complications since we only selected patients discharged directly home. Complications of any kind, except annulus rupture, were more frequent in the late discharge group and 
1 particularly the rate of new pacemaker implantation $(\mathrm{p}<0.001)$, stroke $(\mathrm{p}<0.001)$, vascular complications

$(\mathrm{p}<0.001)$, infectious complications $(\mathrm{p}<0.001)$, and acute kidney injury $(\mathrm{p}<0.001)$ (Table 2).

The results of the multivariable analysis are shown in Table 3 . Variables independently associated with late discharge were female sex, co-morbidities (history of mitral valve prosthesis, respiratory failure, atrial fibrillation, severe pulmonary hypertension) and complications (pacemaker, tamponade, stroke, vascular complications, and acute kidney injury). A history of previous pacemaker implantation was a protective factor (HR $0.83,95 \% \mathrm{CI}: 0.69-0.98, \mathrm{p}=0.031$ ). Interestingly, the use of a self-expandable prosthesis and general anesthesia were also independently associated with late discharge.

We also incorporated into the multivariate model, the center effect which was significantly associated with late discharge (adjusted HR: 5.56, 95\% CI: 4.81-6.42, p<0.001). Interestingly, centers with a shorter LOS more frequently used local anesthesia (73.1\% vs. 52.0\%, p<0.001) and less frequently used self-expandable prosthesis $(24.6 \%$ vs. $33.2 \%, p<0.001)$ as compared to those with prolonged LOS.

We also evaluated the impact of the volume of the centers on LOS. significantly different among low [8 (6-10)], medium [7 (6-9)], and high [7 (5-9)] volume centers (p=0.39). Selfexpandable prosthesis and intra-procedural trans oesophageal echography were more frequently used in low volume centers $(p<0.001)$. The volume of the centers was not predictive of late discharge when integrated in the model (adjusted HR: 1.05, 95\% CI 0.92-1.19, p=0.46). Furthermore, there was no significant correlation between the volume of centers and median LOS (Figure 3).

\section{Safety analysis}

The composite endpoint of all-causes death or repeat hospitalizations within 30 days occurred in 73 (3.3\%) patients in the very early and early discharge groups and in $127(3.5 \%)$ patients in the late discharge group without any significant difference $(\mathrm{p}=0.66)$. Death occurred in $6(0.3 \%)$ patients in the very early early and early discharge groups and in $14(0.4 \%)$ patients in the late discharge group at 30 days $(\mathrm{p}=0.50)$. Repeat hospitalization occurred in 67 (3.0) patients in the very early and early discharge groups and in $113(3.1 \%)$ patients in the late discharge group at 30 days $(\mathrm{p}=0.82)$. Furthermore, 30 -day death or repeat hospitalizations were not significantly different between groups of centers with short or prolonged LOS ( 4.0 vs. $3.2 \%$, $\mathrm{p}=0.16$ ).

We also evaluated the influence of very early and early discharge on long-term outcomes. Very early and early discharge patients had better outcomes since survival, free from repeat hospitalization, was 
1 significantly higher ( $\log$ rank $\mathrm{P}<0.001$, Figure 4A). After propensity score matching, the difference remained

1

2
3

4

5

6

7

8

9

10

11

12

13

14

15

16

17

18

19

20

21

22

23

24

25

26

27

28

29

30

31

32

33

34

35

36

37

38

39

40

41

42

43

44

45

46

47

48

49

50

51

52

53

54

55

56

57

58

59

60

61

62

63

64

65

\section{significant (Figure 4B)}

3 
The main findings of this evaluation of LOS after TF TAVR in patients discharged home are summarized as follows: 1) the median length of stay in our population was highly variable between centers and long (i.e., 6 days) for patients treated by TAVR via a femoral approach; 2) the main determinants of late discharge were female sex, co-morbidities, complications, the use of a self-expandable prosthesis, general anesthesia, and center effect; 3 ) early discharge was safe.

\section{LOS after TAVR}

Currently, there is no recommendation concerning the minimum duration of in hospital monitoring after TAVR and practices are extremely heterogeneous worldwide with considerable differences in LOS in contemporary TAVR registries. The objective of post-TAVR hospital surveillance is to verify the absence of complications (serious complications with TAVR mostly occur within the first 24 to $48 \mathrm{~h}$ of the procedure), the delayed need for pace maker implantation, and to assess the hemodynamic performance of the aortic bioprosthesis by echocardiography before being discharged home or to a rehabilitation center. In France, the LOS remains high although a slight decrease in median LOS has been observed between FRANCE 2 (20102011) and FRANCE TAVI (2013-2015) registries [9 (7-13) vs. 8 (6-11), p<0.001] probably related to lower rates of co-morbidities and complications [12,13]. The FRANCE TAVI database has been frozen for analysis only for the period 2013-2015. During 2016-2018, 14071 TF TAVR patients discharged home have been included in the FRANCE TAVI registry. The median LOS slightly decreased [6 (IQR: 5-7) vs. 7 (IQR: 5-9) days]. In the United States, shorter LOS have recently been reported, with a significant reduction in average LOS between 2012 and 2015 (6.3 vs. 4.6 days, p<0.0001) [14]. In some centers, an early discharge (i.e., < 3days) program has been implemented particularly for transfemoral procedures using a minimalist approach showing that early discharge was feasible and safe [4-11]. There is therefore a considerable heterogeneity of practices concerning the LOS after a TAVR.

\section{Predictive factors of late discharge}

Our study confirmed that co-morbidities and severe complications (tamponade, stroke, vascular complications, and acute kidney injury) were predictive of late discharge [5-11, 15]. Furthermore, as expected, conduction abnormalities (the most frequent complication of TAVI nowadays) requiring the need of a 
1 pacemaker were also associated with prolonged hospitalization while the presence of a pacemaker before TAVR

2 was associated with early discharge. It seems logical that the occurrence of conductive abnormalities after

3 TAVR, requiring or not pacemaker implantation, certainly prolongs in hospital monitoring and delays discharge.

4 Indeed, although most new conduction disturbances occur intraprocedurally, they may occur up to 3 days after

5 intervention. Early discharge in these patients is probably feasible with protocols for arrhythmia monitoring, or early pacemaker indications such as rapid implantation in patients presenting with persistent complete atrioventricular block or severe conduction disorders [15]. Very recently, Rodés-Cabau et al. provide an algorithm strategy for managing conduction disturbances post-TAVR which may reduce unjustified and prolonged monitoring [16]. According to ECG changes/arrhythmias during the procedure and the analysis of the ECG before and after the procedure, the patients are categorized in 5 groups: 1) no ECG changes in patients without right bundle branch block (BBB) pre-procedure; 2) no ECG changes in patients with right BBB preprocedure; 3) ECG changes (increase $>20 \mathrm{~ms}$ in PR or QRS intervals duration) in patients with conduction disturbances (right or left BBB, intraventricular conduction delay with QRS > $120 \mathrm{~ms}$, or first-degree atrioventricular block) preprocedure; 4) new-onset left BBB that persists at the end of the procedure; or 5) transient or persistent high degree atrioventricular block during the procedural period. Interestingly, in the absence of other complications, early discharge is proposed in group 1 at day 1 , in group 2 in the absence of arythmia or ECG changes at day 2, in groups 3 and 4, in case of regression of ECG changes or if no further changes occurred (QRS duration $<150 \mathrm{~ms}$ and/or PR $<240 \mathrm{~ms}$ ) at day 2. Finally, in group 5, patients with persistent high degree atrioventricular block should have early pacemaker. In contrast, patients without recurrence and without conduction abnormalities at day 2 could be discharged early [16].

Interestingly, we also observed that general anaesthesia was significantly and independently associated with prolonged hospitalization. In France, the majority of procedures were still performed using general anaesthesia even though there has been a gradual increase in procedures using local anaesthesia and conscious sedation, from $31.3 \%$ in 2010 to $48.3 \%$ in 2015, according to FRANCE 2 and FRANCE TAVI registries [12, 13]. The impact of the mode of anesthesia on LOS was previously reported with conflicting results. In the UK and STS/ACC US TVT registries, LOS was significantly longer with general anesthesia than local anesthesia $(8.0 \pm 13.5$ vs. $5.7 \pm 5.5$ days, $p<0.0001$ and 6.5 vs. 6.0 days, $p<0.001$; respectively) whereas LOS was not significantly different using general or local anesthesia in the GARY registry [9 (7-13) vs. 9 (7-12) days, $\mathrm{p}=0.11$ ] [17-19]. On the other hand, a recent meta-analysis comparing local and general anesthesia during TAVR procedures has shown that general anesthesia increased hemodynamic instability requiring intra and post 
1 procedural catecholamine treatment, red blood cells transfusion, and pneumoniae resulting in longer hospital and

2 intensive care unit stays [20]. It should be noted that centers that have developed early discharge programs mainly perform TAVR procedures using a minimalist approach with local anesthesia [4-11]. On the other hand, we also observed prolonged LOS using self-expandable as compared to balloon expandable bioprosthesis. We believe that this can be partly explained by the more frequent occurrence of conductive disorders with this type of prosthesis. A retrospective propensity-matched analysis of patients treated with balloon and self-expandable prosthesis also reported increased LOS in intensive care units using self-expandable prosthesis compared to balloon-expandable prosthesis ( $3.4 \pm 4.5$ vs. $2.8 \pm 3.9$ days, $\mathrm{p}=0.016)$ although total LOS was not reported [21]

Only two randomized studies have compared outcomes between self and balloon-expandable transcatheter heart valves. In the CHOICE study, LOS was not reported [22]. More recently, the results of the SOLVE trial (a 2x2 randomized trial of self-expandable vs. balloon-expandable valves and general vs. local anesthesia in patients undergoing TAVR) have been reported. LOS was very high and not significantly different between balloon (Sapien 3) and self-expandable (Evolut R) prosthesis ( $9 \pm 7$ vs. $9 \pm 7$ days, p=0.97) [23]. Moreover, these authors also evaluated the impact of anesthesia strategy on LOS without significant difference between general and local anesthesia ( $9 \pm 7$ vs. $9 \pm 7$ days, p=0.74). Finally, we observed an important center effect on LOS without significant influence of the volume of the center. We believe that this essentially reflects different organizational habits between French centers. It is possible that LOS is also linked to late programming of the next patient (e.g. 7 days later) when the bed is dedicated and reserved for TAVR patients. LOS can also be influenced by prolonged delays to obtain a post-TAVR echocardiography in the absence of anticipation. It is also possible that an unanticipated discharge to a rehabilitation center may prolong the duration of hospitalization although in our analysis we only included patients discharged home.

\section{Safety of early discharge}

As previously reported, we show that early discharge is safe without significant difference in the occurrence of 30-day death or re-admission [4-11]. We also evaluated long-term impact of early and late discharge. We first observed that early discharge was associated with better long-term outcome compared to those discharged late. However, it may also reflect that the better outcomes are related to the fact that patients with shorter LOS had fewer pre-procedure co- morbid conditions and fewer procedural related complications. Interestingly, after propensity score matching, the difference remained significant. While the strategy of early discharge is important from administrative and financial view points; such a practice, may also come with 
1 additional clinical benefits in terms of improved short- and long-term outcomes. However, this result should be

\section{Limitations}

Our study presents some limitations. As a retrospective analysis from a prospective registry, our results should be considered hypothesis generating. Data were site reported and not subject to external validation or adjudication. Furthermore, the reasons for prolonged LOS are not documented in the FRANCE TAVI database. It is therefore possible that other factors contribute to LOS after TAVR. We could not evaluate the influence of ECG changes on LOS since we only had the proportion of patients requiring a pacemaker in the database.

Similarly, we could not also evaluate the impact of frailty on LOS. Finally, we did not evaluate the impact of early ambulation (4 to 6 hours after the procedure) on LOS. Early ambulation is usually part of fast track protocols to favour early discharge [10,11]. Interestingly, the results of the Early Mobilisation after TF-TAVI (MobiTAVI) trial have been recently reported showing that early mobilization was feasible, safe and associated with less infections and urinary catheter use [24].

The amount reimbursed for TAVR procedures in France was based on the level of severity of patients (Levels 1 to 4) and LOS with lower reimbursement when patient are discharged early. It is therefore possible that this may also have an impact on LOS in certain centers. Of note, this has been modified since March 2019 and LOS is no longer linked to reimbursement in France.

On the other hand, we included in this study only patients discharged at home and our results do not apply to patients transferred to another facility or a rehabilitation center.

\section{Conclusions}

Our study reports the high variability of LOS after TF TAVR in France. Determinants of prolonged hospitalization included not only co-morbidities and complications but also the type of transcatheter heart valve and the mode of anesthesia. Early discharge is safe and is potentially associated with better long-term outcomes. Quality of care including prevention and early detection of complication (such as vascular injury, conduction disturbances), early mobilization and early discharge program clearly influence LOS and may outcomes after TF TAVR. 
The authors are grateful to Nikki Sabourin-Gibbs, Rouen University Hospital, for her help in editing the 3 manuscript.

4

5

\section{SOURCES OF FUNDING}

6

Device manufacturers partly funded the registry but had no role in data collection or analysis or in

7 manuscript preparation.

8

9

\section{DISCLOSURES}

10 The authors have no conflict of interest regarding the manuscript. 
1. Baumgartner H, Falk V, Bax JJ, De Bonis M, Hamm C, Holm PJ, Iung B, Lancellotti P, Lansac E, Rodriguez Muñoz D, Rosenhek R, Sjögren J, Tornos Mas P, Vahanian A, Walther T, Wendler O, Windecker S, Zamorano JL; ESC Scientific Document Group (2017) ESC/EACTS Guidelines for the management of valvular heart disease. Eur Heart J 38:2739-2791.

2. Nishimura RA, Otto CM, Bonow RO, Carabello BA, Erwin JP 3rd, Fleisher LA, Jneid H, Mack MJ, McLeod CJ, O'Gara PT, Rigolin VH, Sundt TM 3rd, Thompson A (2017) AHA/ACC Focused Update of the 2014 AHA/ACC Guideline for the Management of Patients With Valvular Heart Disease: A Report of the American College of Cardiology/American Heart Association Task Force on Clinical Practice Guidelines. Circulation 135:e1159-e1195.

3. Kappetein AP, Head SJ, Généreux P, Piazza N, van Mieghem NM, Blackstone EH, Brott TG, Cohen DJ, Cutlip DE, van Es GA, Hahn RT, Kirtane AJ, Krucoff MW, Kodali S, Mack MJ, Mehran R, Rodés-Cabau J, Vranckx P, Webb JG, Windecker S, Serruys PW, Leon MB (2012) Updated standardized endpoint definitions for transcatheter aortic valve implantation: the Valve Academic Research Consortium-2 consensus document. J Am Coll Cardiol 60:1438-1454.

4. Durand E, Borz B, Godin M, Tron C, Litzler PY, Bessou JP, Bejar K, Fraccaro C, Sanchez-Giron C, Dacher JN, Bauer F, Cribier A, Eltchaninoff H (2012) Transfemoral aortic valve replacement with the Edwards SAPIEN and Edwards SAPIEN XT prosthesis using exclusively local anesthesia and fluoroscopic guidance: feasibility and thirty-day outcomes. JACC Cardiovasc Interv 5:461-467.

5. Durand E, Eltchaninoff H, Canville A, Bouhzam N, Godin M, Tron C, Rodriguez C, Litzler PY, Bauer F, Cribier A (2015) Feasibility and safety of early discharge after transfemoral transcatheter aortic valve implantation with the Edwards SAPIEN-XT prosthesis. Am J Cardiol 115:1116-1122.

6. Serletis-Bizios A, Durand E, Cellier G, Tron C, Bauer F, Glinel B, Dacher JN, Cribier A, Eltchaninoff H (2016) A Prospective Analysis of Early Discharge After Transfemoral Transcatheter Aortic Valve Implantation. Am J Cardiol 118:866-872.

7. Barbanti M, Capranzano P, Ohno Y, Attizzani GF, Gulino S, Immè S, Cannata S, Aruta $P$, Bottari V, Patanè M, Tamburino C, Di Stefano D, Deste W, Giannazzo D, Gargiulo G, Caruso G, Sgroi C, Todaro D, di Simone E, Capodanno D, Tamburino C (2015) Early discharge after transfemoral transcatheter aortic valve implantation. Heart 101:1485-1490. 
1 8. Kamioka N, Wells J, Keegan P, Lerakis S, Binongo J, Corrigan F, Condado J, Patel A, Forcillo J, Ogburn L,

Dong A, Caughron H, Simone A, Leshnower B, Devireddy C, Mavromatis K, Guyton R, Stewart J, Thourani V, Block PC, Babaliaros V (2018) Predictors and clinical outcomes of next-day discharge after minimalist transfemoral transcatheter aortic valve replacement. JACC Cardiovasc Interv 11:107-115.

9. Kotronias RA, Teitelbaum M, Webb JG, Mylotte D, Barbanti M, Wood DA, Ballantyne B, Osborne A, Solo K, Kwok CS, Mamas MA, Bagur R (2018) Early versus standard discharge after transcatheter aortic valve replacement: a systematic review and meta-analysis. JACC Cardiovasc Interv 11:1759-1711.

10. Barbanti M, van Mourik MS, Spence MS, Icovelli F, Martinelli 1 GL, Muir DF, Saia F, Bortone AS, Densem CG, van der Kley F, Bramlage P, Vis M, Tamburino C (2019) Optimizing Patient Discharge Management after Transfemoral Transcatheter Aortic Valve Implantation: The Multicentre European FAST-TAVI Trial. EuroIntervention 15:147-154.

11. Wood DA, Lauck SB, Cairns JA, Humphries KH, Cook R, Welsh R, Leipsic J, Genereux P, Moss R, Jue J, Blanke P, Cheung A, Ye J, Dvir D, Umedaly H, Klein R, Rondi K, Poulter R, Stub D, Barbanti M, Fahmy P, Htun N, Murdoch D, Prakash R, Barker M, Nickel K, Thakkar J, Sathananthan J, Tyrell B, Al-Qoofi F, Velianou JL, Natarajan MK, Wijeysundera HC, Radhakrishnan S, Horlick E, Osten M, Buller C, Peterson M, Asgar A, Palisaitis D, Masson JB, Kodali S, Nazif T, Thourani V, Babaliaros VC, Cohen DJ, Park JE, Leon MB, Webb JG (2019) The Vancouver 3M (Multidisciplinary, Multimodality, But Minimalist) Clinical Pathway Facilitates Safe Next-Day Discharge Home at Low-, Medium-, and High-Volume Transfemoral Transcatheter Aortic Valve Replacement Centers: The 3M TAVR Study. JACC Cardiovasc Interv 12:459469.

12. Auffret V, Lefevre T, Van Belle E, Eltchaninoff H, Iung B, Koning R, Motreff P, Leprince P, Verhoye JP, Manigold T, Souteyrand G, Boulmier D, Joly P, Pinaud F, Himbert D, Collet JP, Rioufol G, Ghostine S, Bar O, Dibie A, Champagnac D, Leroux L, Collet F, Teiger E, Darremont O, Folliguet T, Leclercq F, Lhermusier T, Olhmann P, Huret B, Lorgis L, Drogoul L, Bertrand B, Spaulding C, Quilliet L, Cuisset T, Delomez M, Beygui F, Claudel JP, Hepp A, Jegou A, Gommeaux A, Mirode A, Christiaens L, Christophe C, Cassat C, Metz D, Mangin L, Isaaz K, Jacquemin L, Guyon P, Pouillot C, Makowski S, Bataille V, Rodés-Cabau J, Gilard M, Le Breton H; FRANCE TAVI Investigators (2017) Temporal trends in transcatheter aortic valve replacement in France: FRANCE 2 to 1 FRANCE TAVI. J Am Coll Cardiol 70:42-55. 
13. Gilard M, Eltchaninoff H, Iung B, Donzeau-Gouge P, Chevreul K, Fajadet J, Leprince P, Leguerrier A, Lievre M, Prat A, Teiger E, Lefevre T, Himbert D, Tchetche D, Carrié D, Albat B, Cribier A, Rioufol G, Sudre A, Blanchard D, Collet F, Dos Santos P, Meneveau N, Tirouvanziam A, Caussin C, Guyon P, Boschat J, Le Breton H, Collart F, Houel R, Delpine S, Souteyrand G, Favereau X, Ohlmann P, Doisy V, Grollier G, Gommeaux A, Claudel JP, Bourlon F, Bertrand B, Van Belle E, Laskar M; FRANCE 2 Investigators (2012) Registry of transcatheter aortic-valve implantation in high-risk patients. N Engl J Med 366:1705-1715.

14. Grover FL, Vemulapalli S, Carroll JD, Edwards FH, Mack MJ, Thourani VH, Brindis RG, Shahian DM, Ruiz CE, Jacobs JP, Hanzel G, Bavaria JE, Tuzcu EM, Peterson ED, Fitzgerald S, Kourtis M, Michaels J, Christensen B, Seward WF, Hewitt K, Holmes DR Jr; STS/ACC TVT Registry (2017) 2016 Annual report of the Society of Thoracic Surgeons/American College of Cardiology transcatheter valve therapy registry. J Am Coll Cardiol 69:1215-1230.

15. Mirolo A, Viart G, Durand E, Savouré A, Godin B, Auquier N, Raitière O, Eltchaninoff H, Anselme F (2018) Pacemaker memory in post-TAVI patients: Who should benefit from permanent pacemaker implantation? Pacing Clin Electrophysiol 41:1178-1184.

16. Rodés-Cabau J, Ellenbogen KA, Krahn AD, Latib A, Mack M, Mittal S, Muntané-Carol G, Nazif TM, Sondergaard L, Urena M, Windecker S, Philippon F (2019) Management of Conduction Disturbances Associated With Transcatheter Aortic Valve Replacement: JACC Scientific Expert Panel. J Am Coll Cardiol 74:1086-1106.

17. Mallikethi-Reddy S, Akintoye E, Telila T, Sudhakar R, Jagadeesh K, Briasoulis A, Rubenfire M, Afonso L, Grines CL (2017) Transcatheter aortic valve implantation in the United States: Predictors of early hospital discharge. J Interv Cardiol 30:149-155.

18. Eskandari M, Aldalati O, Dworakowski R, Byrne JA, Alcock E, Wendler O, MacCarthy PA, Ludman PF, Hildick-Smith DJR, Monaghan MJ; UK TAVI Steering Committee and the National Institute for Cardiovascular Outcome Research (2018) Comparison of general anaesthesia and non-general anaesthesia approach in transfemoral transcatheter aortic valve implantation. Heart 104:1621-1628.

19. Husser O, Fujita B, Hengstenberg C, Frerker C, Beckmann A, Möllmann H, Walther T, Bekeredjian R, Böhm M, Pellegrini C, Bleiziffer S, Lange R, Mohr F, Hamm CW, Bauer T, Ensminger S; GARY Executive Board (2018) Conscious sedation versus general anesthesia in transcatheter aortic valve replacement: the German Aortic Valve Registry. JACC Cardiovasc Interv 11:567-578. 
20. Ehret C, Rossaint R, Foldenauer AC, Stoppe C, Stevanovic A, Dohms K, Hein M, Schälte G (2017) Is local anaesthesia a favourable approach for transcatheter aortic valve implantation? A systematic review and meta-analysis comparing local and general anaesthesia. BMJ Open. 7:e016321.

21. Wijeysundera HC, Qiu F, Koh M, Prasad TJ, Cantor WJ, Cheema A, Chu MW, Czarnecki A, Feindel C, Fremes SE, Kingsbury KJ, Natarajan MK, Peterson M, Ruel M, Strauss B, Ko DT (2017) Comparison of outcomes of balloon-expandable versus self-expandable transcatheter heart valves for severe aortic stenosis. Am J Cardiol 119:1094-1099.

22. Abdel-Wahab M, Mehilli J, Frerker C, Neumann FJ, Kurz T, 1 Tolg R, Zachow D, MD Guerra E, Massberg S, Schafer U, El-Mawardy M, Richardt G, for the CHOICE investigators (2014) Comparison of balloonexpandable vs. self-expandable valves in patients undergoing transcatheter aortic valve replacement: The CHOICE randomized clinical trial. JAMA 311:1503-1514.
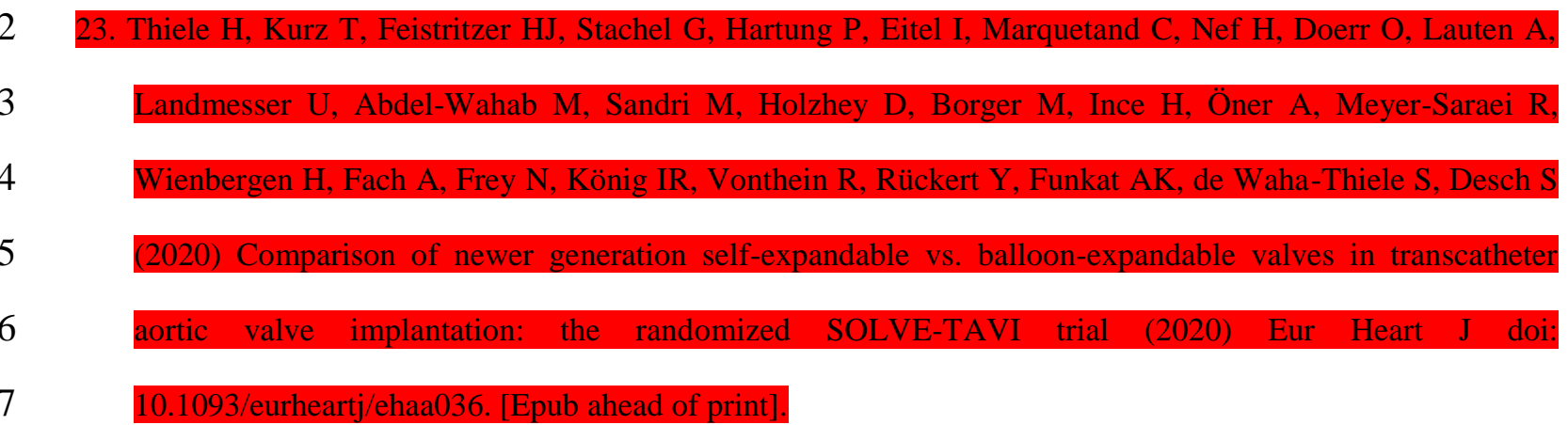

24. Vendrik J, Vlastra W, van Mourik MS, Delewi R, Beijk MA, Lemkes J, Wykrzykowska JJ, de Winter RJ,

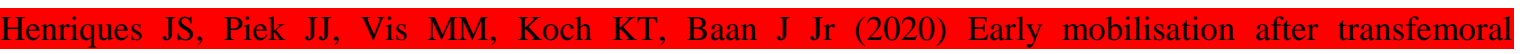
transcatheter aortic valve implantation: results of the MobiTAVI trial. Neth Heart J doi: 10.1007/s12471-

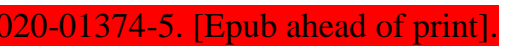


1

2

3

4

5

6 7
2

3 Figure 1. Title: Flowchart. Legend: Description of the studied population.

4 Figure 2. Title: Boxplot analysis of length of stay according to centers. Legend: length of stay was extremely 5 variable among centers.

6 Figure 3. Title: Correlation between length of stay and volume of activity. Legend: There was no significant 7 correlation between length of stay and volume of centers.

8 Figure 4. Title: Survival free from rehospitalization in the overall population (A) and after propensity score

9 matching (B). Legend: Plot of survival free from hospitalization in early versus late discharge groups. The 
Table 1. Baseline characteristics

\begin{tabular}{|c|c|c|c|c|}
\hline Variables & $\begin{array}{c}\text { Very early } \\
\text { discharge } \\
\text { group } \\
(\mathrm{N}=256)\end{array}$ & $\begin{array}{c}\text { Early } \\
\text { discharge } \\
\text { group } \\
(\mathrm{N}=1977)\end{array}$ & $\begin{array}{c}\text { Late } \\
\text { discharge } \\
\text { group } \\
(\mathrm{N}=3624)\end{array}$ & $\mathbf{P}$ \\
\hline Age (years) & $83.0 \pm 7.3$ & $82.7 \pm 7.3$ & $82.6 \pm 7.3$ & 0.58 \\
\hline Male, n (\%) & $126(49.2)$ & $894(45.2)$ & $1837(50.7)$ & $<0.001$ \\
\hline BMI $\left(\mathrm{Kg} / \mathrm{m}^{2}\right)$ & $26.7 \pm 6.1$ & $26.6 \pm 5.1$ & $26.6 \pm 4.9$ & 0.99 \\
\hline Diabetes, n (\%) & $59(23.0)$ & $471(23.8)$ & $926(25.6)$ & 0.28 \\
\hline Previous CABG, n (\%) & $19(7.4)$ & $233(11.8)$ & $414(11.4)$ & 0.12 \\
\hline Previous PCI, n (\%) & $56(21.9)$ & $573(29.0)$ & $1033(28.5)$ & 0.06 \\
\hline Previous SAVR, n (\%) & $13(5.1)$ & $97(4.9)$ & $171(4.7)$ & 0.93 \\
\hline Previous SMVR, n (\%) & $3(1.2)$ & $10(0.5)$ & $52(1.4)$ & 0.03 \\
\hline PAD, n (\%) & $30(11.7)$ & $349(17.7)$ & $595(16.4)$ & 0.05 \\
\hline COPD, n (\%) & $41(16.0)$ & $341(17.2)$ & $720(19.9)$ & 0.03 \\
\hline Previous stroke, n (\%) & $26(10.2)$ & $176(8.9)$ & $380(10.5)$ & 0.16 \\
\hline Previous pacemaker, n (\%) & $42(16.4)$ & $310(15.7)$ & $476(13.1)$ & 0.02 \\
\hline Recent MI, n (\%) & $5(2.0)$ & $22(1.1)$ & $57(1.6)$ & 0.30 \\
\hline Severe renal insufficiency, n $(\%)$ & $12(4.7)$ & $160(8.1)$ & $349(9.6)$ & 0.01 \\
\hline Creatinine clearance $(\mathrm{ml} / \mathrm{min})$ & $54.5 \pm 19.6$ & $57.5 \pm 23.8$ & $56.9 \pm 24.5$ & 0.47 \\
\hline Atrial fibrillation, n (\%) & $66(25.8)$ & $521(26.4)$ & $1118(30.9)$ & 0.001 \\
\hline NYHA 3-4, n (\%) & $157(61.3)$ & $1185(59.9)$ & $2278(62.9)$ & 0.09 \\
\hline Log. EuroSCORE (\%) & $14.8 \pm 8.4$ & $17.7 \pm 10.8$ & $19.5 \pm 11.3$ & $<0.001$ \\
\hline MR grade 3-4, n (\%) & $6(2.3)$ & $48(2.4)$ & $79(2.2)$ & 0.91 \\
\hline Severe PH, n (\%) & $19(7.4)$ & $159(8.0)$ & $417(11.5)$ & $<0.001$ \\
\hline Mean aortic gradient (mmHg) & $46.9 \pm 16.7$ & $48.0 \pm 15.7$ & $47.4 \pm 15.6$ & 0.30 \\
\hline Aortic area $\left(\mathrm{cm}^{2}\right)$ & $0.71 \pm 0.25$ & $0.69 \pm 0.18$ & $0.69 \pm 0.22$ & 0.35 \\
\hline LVEF (\%) & $58.0 \pm 14.2$ & $56.2 \pm 13.4$ & $55.7 \pm 13.1$ & 0.03 \\
\hline
\end{tabular}

3 Abbreviations: BMI: body mass index, CABG: coronary artery bypass graft, PCI: percutaneous coronary

4 intervention, SAVR: surgical aortic valve replacement, SMVR: surgical mitral valve replacement, PAD:

5 peripheral arterial disease, COPD: chronic obstructive pulmonary disease, MI: myocardial infarction, MR: mitral

6 regurgitation, PH: pulmonary hypertension, LVEF: left ventricular ejection fraction, NYHA: New York Heart

7 Association. 
Table 2. In-hospital outcomes

\begin{tabular}{|c|c|c|c|c|}
\hline Variables & $\begin{array}{c}\text { Very early } \\
\text { discharge } \\
\text { group } \\
(\mathrm{N}=256)\end{array}$ & $\begin{array}{c}\text { Early } \\
\text { discharge } \\
\text { group } \\
(\mathrm{N}=1977)\end{array}$ & $\begin{array}{c}\text { Late } \\
\text { discharge } \\
\text { group } \\
(\mathrm{N}=3624)\end{array}$ & $\mathbf{P}$ \\
\hline Lenght of stay (days) & $2.8 \pm 0.4$ & $5.1 \pm 0.8$ & $10.2 \pm 5.4$ & $<0.001$ \\
\hline Local anesthesia, n (\%) & $219(85.5)$ & $1124(56.9)$ & $2030(56.0)$ & $<0.001$ \\
\hline TEE, n (\%) & $16(6.3)$ & $421(21.3)$ & $958(26.4)$ & $<0.001$ \\
\hline Balloon expandable valve, $\mathrm{n}(\%)$ & $229(89.5)$ & $1500(75.9)$ & $2315(63.9)$ & $<0.001$ \\
\hline Procedural success, n (\%) & $255(99.6)$ & $1954(98.8)$ & $3547(97.9)$ & 0.01 \\
\hline Annulus rupture, n (\%) & $0(0)$ & $1(0.1)$ & $4(0.1)$ & 0.60 \\
\hline Coronary obstruction, n (\%) & $0(0)$ & $0(0)$ & $9(0.2)$ & 0.01 \\
\hline New MI, n (\%) & $0(0)$ & $0(0)$ & $7(0.2)$ & 0.11 \\
\hline New pacemaker, n (\%) & $12(4.7)$ & $106(5.4)$ & $719(19.8)$ & $<0.001$ \\
\hline Tamponnade, n (\%) & $1(0.4)$ & $5(0.3)$ & $41(1.1)$ & 0.002 \\
\hline Cardiac surgery, n (\%) & $0(0)$ & $0(0)$ & $9(0.2)$ & 0.06 \\
\hline Stroke, n (\%) & $0(0)$ & $1(0.1)$ & $34(0.9)$ & $<0.001$ \\
\hline Vascular complication, $\mathrm{n}(\%)$ & $8(3.1)$ & $68(3.4)$ & $282(7.8)$ & $<0.001$ \\
\hline Infectious complication, n (\%) & $1(0.4)$ & $10(0.5)$ & $133(3.7)$ & $<0.001$ \\
\hline Valve migration, $\mathrm{ml} / \mathrm{min}$ & $0(0)$ & $7(0.4)$ & $31(0.9)$ & 0.03 \\
\hline Two valves, n (\%) & $0(0)$ & $17(0.9)$ & $59(1.6)$ & 0.007 \\
\hline AKI, n (\%) & $0(0)$ & $15(0.8)$ & $117(3.2)$ & $<0.001$ \\
\hline Any complication, n (\%) & $39(15.2)$ & $414(20.9)$ & $1784(49.3)$ & $<0.001$ \\
\hline
\end{tabular}

3 Abbreviations: TEE: trans oesophageal echocardiography, MI: myocardial infarction, AKI: acute kidney injury 
Table 3. Multivariable analysis for risk factors of late discharge

\begin{tabular}{|c|c|c|c|}
\hline & Hazard ratio & $95 \% \mathrm{CI}$ & $\mathbf{P}$ \\
\hline Center effect & 5.3 & $4.6-6.2$ & $<0.001$ \\
\hline Gender (female) & 1.3 & $1.1-1.4$ & $<0.001$ \\
\hline BMI (per $\left.1 \mathrm{Kg} / \mathrm{m}^{2}\right)$ & 1.0 & $0.9-1.0$ & 0.76 \\
\hline LVEF (per $1 \%$ increase) & 1.0 & $0.9-1.0$ & 0.72 \\
\hline NYHA (3-4 vs. 1-2) & 1.1 & $0.9-1.2$ & 0.32 \\
\hline Previous SMVR & 2.6 & $1.3-5.2$ & 0.004 \\
\hline COPD & 1.3 & $1.1-1.5$ & 0.003 \\
\hline Severe renal insufficiency & 1.2 & $0.9-1.4$ & 0.18 \\
\hline Previous stroke & 1.2 & $0.9-1.5$ & 0.10 \\
\hline Previous pacemaker & 0.8 & $0.7-0.9$ & 0.04 \\
\hline Atrial fibrillation & 1.4 & $1.2-1.6$ & $<0.001$ \\
\hline Severe PH (> 60 mmHg) & 1.3 & $1.1-1.6$ & 0.01 \\
\hline General anesthesia & 1.5 & $1.3-1.8$ & $<0.001$ \\
\hline Intra-procedural TEE & 1.3 & $1.1-1.6$ & 0.002 \\
\hline $\begin{array}{l}\text { Self-expandable vs balloon } \\
\text { expandable valve }\end{array}$ & 1.7 & $1.5-2.0$ & $<0.001$ \\
\hline Procedural success & 0.8 & $0.3-2.1$ & 0.61 \\
\hline Valve migration & 1.7 & $0.6-4.8$ & 0.29 \\
\hline New pacemaker & 4.4 & $3.5-5.5$ & $<0.001$ \\
\hline Tamponade & 10.1 & $2.9-35.1$ & $<0.001$ \\
\hline Stroke & 31.9 & $4.2-242.8$ & 0.001 \\
\hline Vascular complication & 2.8 & $2.1-3.8$ & $<0.001$ \\
\hline AKI & 4.7 & $2.6-8.4$ & $<0.001$ \\
\hline Two valves & 1.3 & $0.4-4.4$ & 0.61 \\
\hline
\end{tabular}

3 Abbreviations: BMI: body mass index, LVEF: left ventricular ejection fraction, NYHA: New York Heart

4 Association, SMVR: surgical mitral valve replacement, COPD: chronic obstructive pulmonary disease, PH:

5 pulmonary hypertension, TEE: trans oesophageal echocardiography, AKI: acute kidney injury. 


\section{TAVI patients}

\section{6 non-TF patients}

\section{TF patients}
6 Centera
32 Direct Flow
44 Lotus
5 Portico
6 Others

\section{Sapien 3607 CoreValve}

\section{7 discharged home}




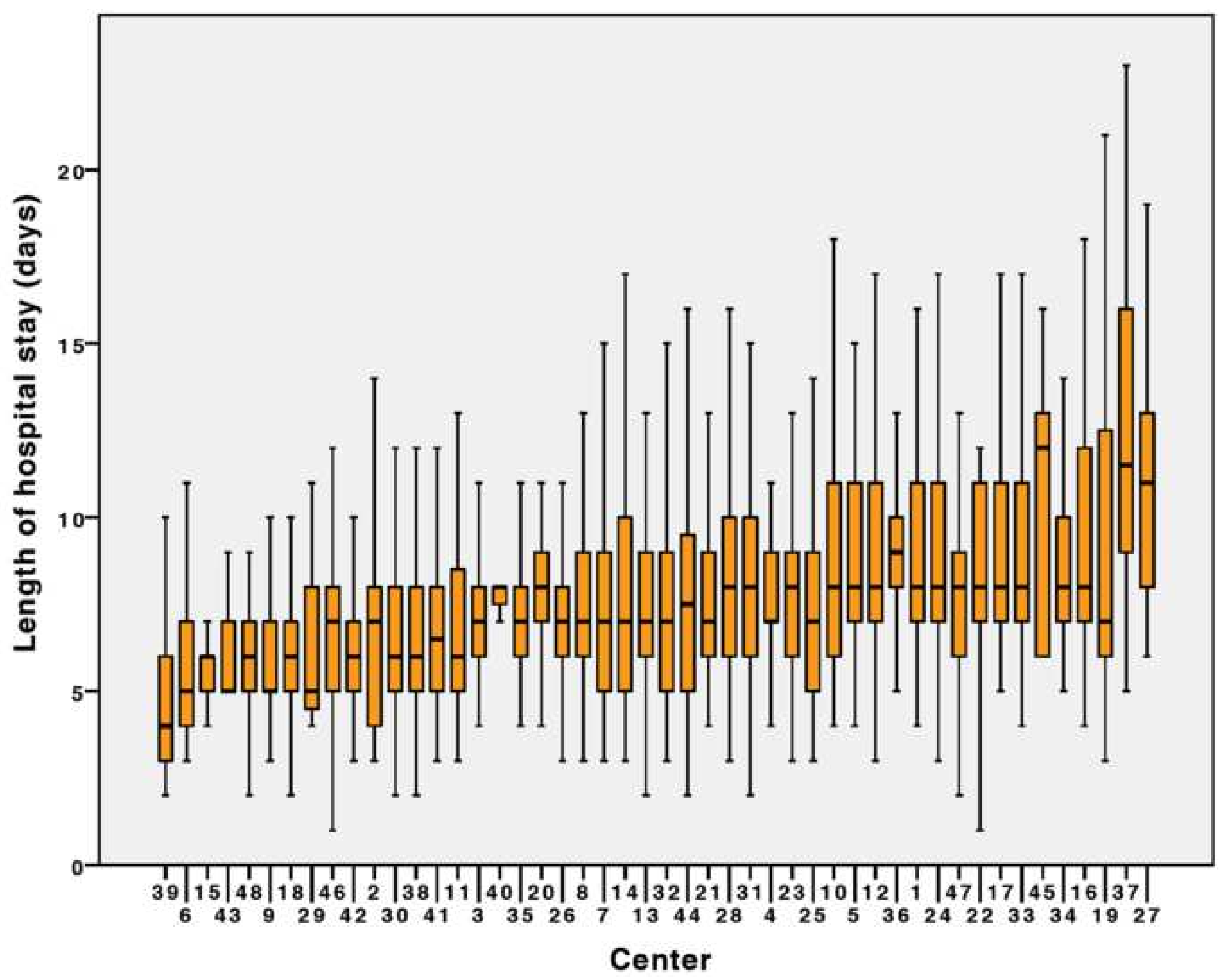




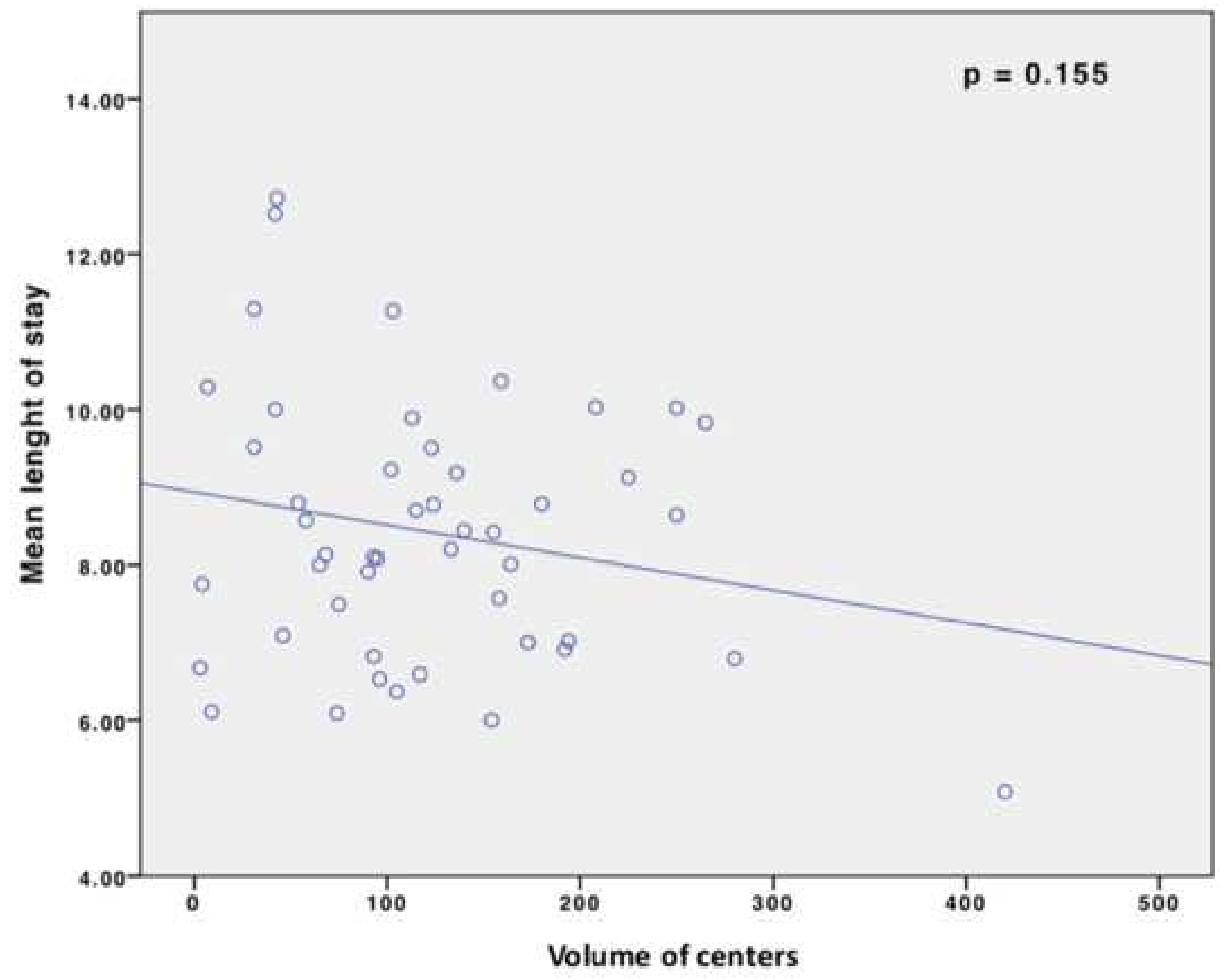


A

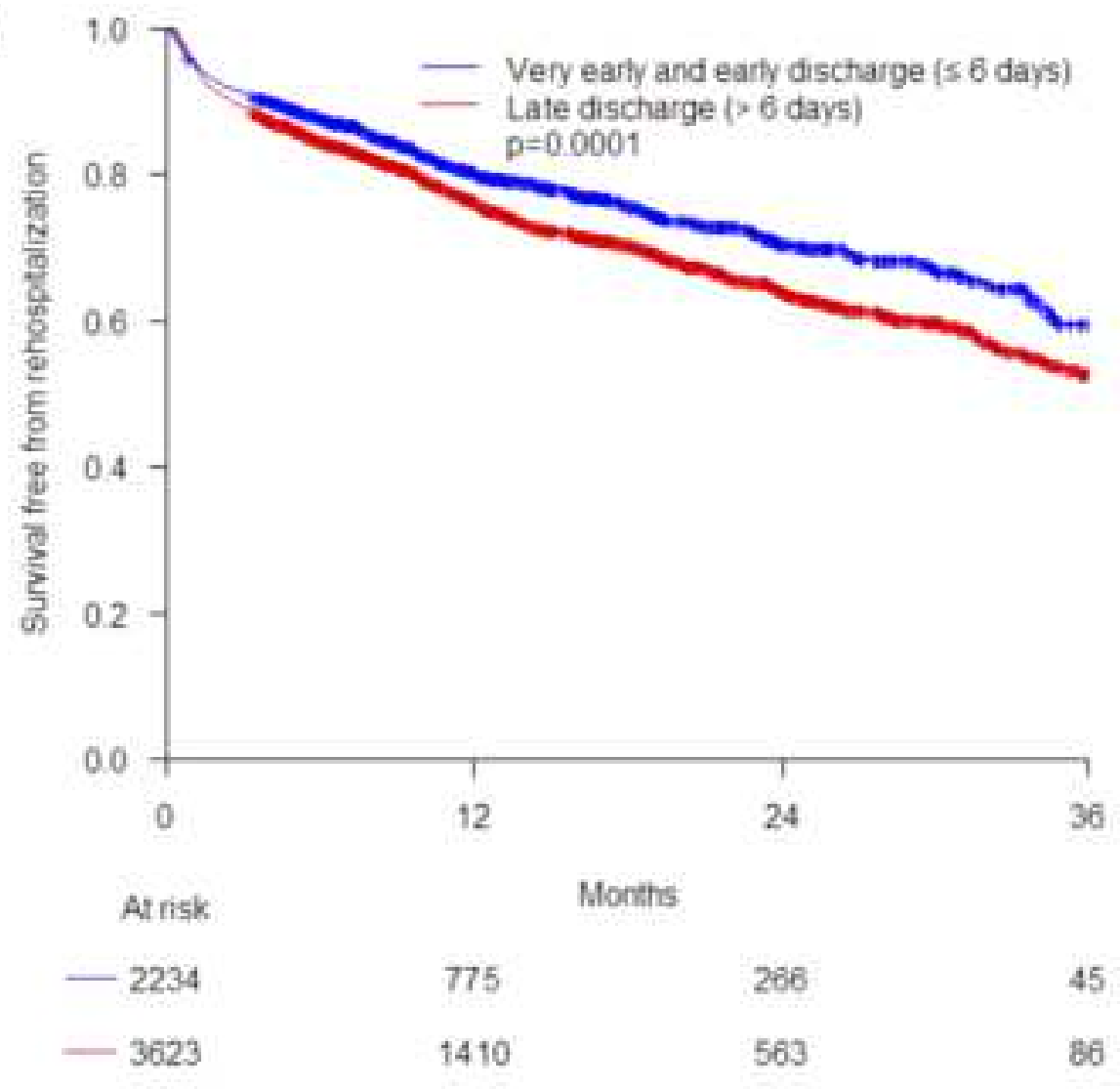

B

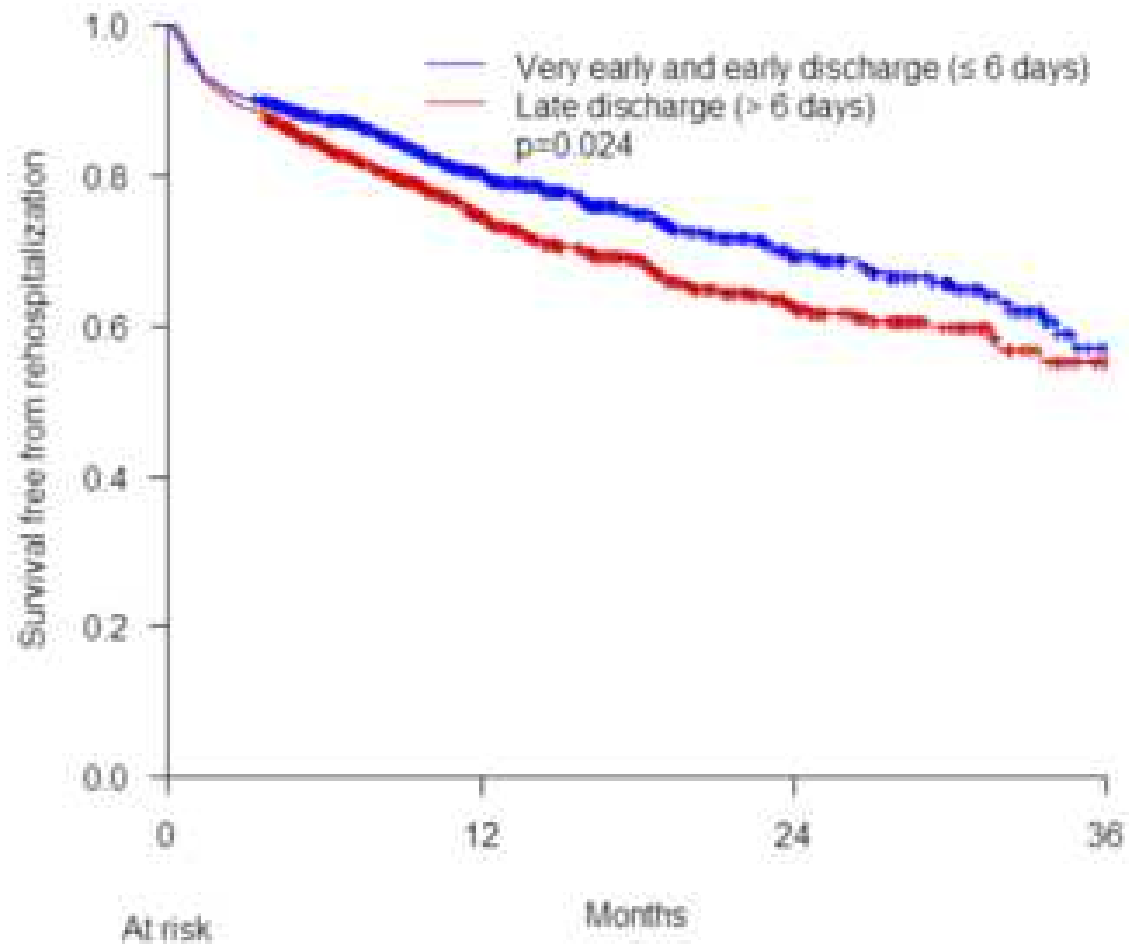

$-1177$

453

157

27

$-1177$

413

144

20

7




\section{Durand et al., manuscript number CRCD-D-19-00933: response to Reviewers}

\section{Responses to the Reviewer 1}

The following are numbered consecutively with the queries of Reviewer 1

1. The authors report interesting register data from France concerning the length of hospital stay according to TAVI.

We thank the reviewer for his/her laudatory comment.

2. The multivariate analysis identified among others a centre effect, atrial fibrillation, TEE, valve type, type of anaesthesia or pacemaker neediness as influencing factors. In the discussion, the influence of ECG changes or predictive ECG changes is correctly considered; unfortunately, no further information can be found. It would be helpful to describe the ECG before and after TAVI, separated by groups.

We agree with the Reviewer's concern. However, the description of ECG before and after TAVR was not available in the database of the FRANCE TAVI registry. We only have the proportion of patients with an history of pacemaker before TAVI and the incidence of pacemaker after TAVI. This has been underlined in the limitation section of the revised manuscript page 12, lines 9-10.

3. Furthermore, it is noticeable that the topic of center and anesthesia is not considered more closely. Possibly the center effect is based on the fact that there are differences in the frequency of local anesthesia.

As required by the Reviewer, we evaluated the incidence of local anesthesia according to the center effect. As expected, centers with a shorter LOS more frequently used local anesthesia as compared to those with prolonged LOS $(73.1 \%$ vs. 52.0\%, p<0.001). Nevertheless, when these two variables were included in the multivariate model they remained independently associated with prolonged LOS suggesting that the center effect is not only related to the proportion of local anesthesia. This has been added in the revised manuscript page $\underline{7 \text {, lines } 10-12}$. 


\section{Responses to the Reviewer 3}

The following are numbered consecutively with the queries of Reviewer 3

Authors assessed the length of hospital stay in the French TAVR registry. As expected, longer hospital stay was associated with female sex, co-morbidities, major complications, self expandable valve, general anesthesia, and center.

1. I would strongly recommend to look into patients with very early discharge and grade into 3 groups (e.g. 1-3 days, $>3-<7$, and $>7$ days). This may provide interesting insights, particularly in times where low-risk patients are increasingly being treated.

As suggested by the Reviewer, we have added "a very early discharge "group in the revised manuscript. Data are shown in tables 1 and 2 in the revised manuscript pages 19 and $\underline{20}$. The proportion of patients with very early discharge ( $\leq 3$ days) was low $(4.4 \%)$. Given the small number of patients discharged very early, the multivariate analysis (table 3 ) has not been modified.

2. Center experience impacted the length of hospital stay. Please detail how low, medium and high volume was defined.

We agree with the Reviewer's concern. Using tertiles values of the number of patients treated by centers, we defined Low $(<75)$, medium $(75-140)$ and high volume $(>140)$ centers. This has been added in the revised manuscript page 5, lines 6-7. We also added in the revised manuscript (page 7, lines 13-14) the median LOS in the 3 groups and the difference was not significant

3. Self-expandable valves and use of TEE were associated with longer hospital stay. This may be related to center experience as well. Please comment.

We agree with the Reviewer that self-expandable valves and use of TEE were associated with longer hospital stay. As suggested by the Reviewer, we evaluated the use of TEE and selfexpandable valves according to the volume of center (Low, medium, and high volume). The results are summarized below:

\begin{tabular}{|l|c|c|c|c|}
\hline & Low & Medium & High & P \\
\hline Self-expandable valve, \% & 37.4 & 37.7 & 26.1 & $<0.001$ \\
\hline TEE, \% & 37.6 & 9.9 & 29.1 & $<0.001$ \\
\hline
\end{tabular}

Self-expandable valves were less frequently used in high volume centers and TEE was less frequently used in medium and high-volume centers. This has been added in the revised manuscript page 7 , lines 14-16.

4. I assume, figure 4 depicts non-matched patients. If so, I would suggest to perform a matched-pair analysis because the groups are very different.

We agree with the Reviewer's concern. We did a propensity score matching based on a logistic regression model including baseline age, gender, logistic EuroSCORE for predicted risk of surgical mortality, chronic obstructive pulmonary disorder, atrial fibrillation, history of surgical mitral valve replacement, local anesthesia, model of prosthesis, stroke, vascular complication, acute kidney injury, and pacemaker, as covariates. This has been added in the revised manuscript in the method section page 5, lines 15-26. Interestingly, after propensity score matching, very early and early discharge patients had improved outcomes as 
compared to those discharge late. This has been added in the revised manuscript in Figure 4B. However, this result should be analyzed with caution, as it is possible that the difference observed is linked to the persistence of residual confounding factors. This has been added in the revised manuscript page 12 , lines 1-3.

5. The SOLVE trial has been published, please cite accordingly (Thiele H, Eur Heart J. 2020 Feb 12. pii: ehaa036. doi: 10.1093/eurheartj/ehaa036). Same with the MobiTAVI study, Vendrik J, Neth Heart J. 2020 Feb 28. doi: 10.1007/s12471-020-01374-5.

When we submitted the manuscript, these two studies were not published. These two references $(23,24)$ have been therefore added in the revised manuscript page 17, lines 12-21. 


\section{Click here to access/download
Supplementary Material
letter to the editor.doc \\ Click here to access/download
Supplementary Material
letter to the editor.doc Click here to access/download
Supplementary Material
letter to the editor.doc}

